\title{
THE END OF PROGRESS: CONTRIBUIÇÕES, QUESTIONAMENTOS E CRÍTICAS DE CLAUDIA LEEB Å OBRA DE AMY ALLEN
}

\author{
José Ribamar Mendes Júnior* \\ Yuri Anderson Pereira Jurubeba ${ }^{* *}$
}

Resumo: Em seu livro, The End of Progress, Amy Allen parte da crítica ao eurocentrismo formulada pela teoria pós-colonial e busca demonstrar como os principais pensadores da terceira geração da Escola de Frankfurt contam com noções substantivas de progresso histórico. O presente trabalho exibe um breve escorço acerca da hipótese de Amy Allen, seguido de críticas e questionamentos suscitados pela Professora Claudia Leeb, Professora Associada de Teoria Política da Washington State University, sempre na perspectiva do refinamento argumentativo.

Palavras-chave: The End of Progress; Amy Allen; Claudia Leeb; Escola de Frankfurt; teoria crítica.

\section{THE END OF PROGRESS: CLAUDIA LEEB'S CONTRIBUTIONS, QUESTIONS AND REVIEWS TO AMY ALLEN'S WORK}

\begin{abstract}
In her book, The End of Progress, Amy Allen starts from the critique of Eurocentrism formulated by postcolonial theory and seeks to demonstrate how the leading thinkers of the third generation of the Frankfurt School rely on substantive notions of historical progress. This paper presents a brief review of Amy Allen's hypothesis, followed by criticisms and questions raised by Professor Claudia Leeb, Associate Professor of Political Theory at Washington State University, always from the perspective of argumentative refinement.
\end{abstract}

Keywords: The End of Progress; Amy Allen; Claudia Leeb; Frankfurt School; critical theory.

\section{INTRODUÇÃO}

Em seu livro, The End of Progress, Amy Allen embarca em um projeto ambicioso: decolonizar a teoria crítica contemporânea da Escola de Frankfurt. O título do livro foi

\footnotetext{
* Doutorando em Desenvolvimento Regional pela Universidade Federal do Tocantins - UFT. Doutorando em Teoria do Estado e Direito Constitucional pela Pontifícia Universidade Católica do Rio de Janeiro - PUC-Rio. Mestre em Prestação Jurisdicional e Direitos Humanos pela Universidade Federal do Tocantins - UFT. Mestre em Direito Constitucional pela Universidade de Lisboa - FDUL. Juiz de Direito de $3^{a}$ Entrância do Poder Judiciário do Estado do Tocantins. E-mail: vrmendes@uol.com.br. Endereço postal: Avenida Orla, Quadra 38, Lote 3A, Praia da Graciosa, Palmas, Tocantins, CEP. 77026-005.

** Doutorando em Direito pela PUC-Rio. Mestre em Prestação Jurisdicional e Direitos Humanos pela Universidade Federal do Tocantins (UFT). Professor da Universidade Estadual do Tocantins (UNITINS). Assessor Jurídico de Desembargador do Tribunal de Justiças do Estado do Tocantins. E-mail: yuri.jurubeba@yahoo.com.br. Endereço postal: quadra 205 sul, Alameda 13, Lote HM 01, apt. 1301, plano diretor sul, Palmas. Tocantins, CEP. 77015-264.
}

Teorias do Direito e Realismo Jurídico | e-ISSN: 2525-9601 | Encontro Virtual | v. 7 | n. 2 | 
inspirado nas palestras de Theodor Adorno sobre progresso, nas quais o argumento de que "o progresso ocorre apenas quando atinge um objetivo" é recorrente (2016, p. 07). Apesar de a preocupação de Adorno com o progresso ser diferente da preocupação da autora - a dele ligada ao horror de Auschwitz e à ameaça de uma guerra nuclear -, a autora compartilha a ideia que considera central da proposta de Adorno, qual seja: disseminar leituras ideológicas falsas da História, em termos de progresso, é necessário para o progresso político-moral no futuro. Em outras palavras, a ideia-chave de Adorno que a autora quer reiterar na obra é a dissociação de afirmações quanto à possibilidade de progresso futuro daquilo que chama de "progresso como um imperativo político-moral” de leituras da História como uma história de progresso, o que ela chama de "progresso como "fato".

Em sua obra, Allen se esforça para evitar fazer afirmações sem apoiá-las por meio de uma leitura textual cuidadosa dos pensadores com quem ela se baseia. Busca a autora, primeiro, desenvolver uma crítica imanente de vários importantes e representativos teóricos críticos da Escola de Frankfurt contemporâneos com relação a suas respectivas concepções de "progresso" e, em segundo lugar, colocar essa crítica imanente a propósitos decoloniais.

A autora parte da crítica ao eurocentrismo formulada pela teoria pós-colonial e busca demonstrar como os principais pensadores da terceira geração da Escola de Frankfurt contam com noções substantivas de progresso histórico. Allen demonstra que uma concepção normativa da modernidade como progresso histórico é central para a reconstrução pósfundacional da Teoria Crítica na era do pós-guerra, seja na obra de Jürgen Habermas, Axel Honneth ou Rainer Forst. Um dos pontos fortes do livro é a maneira cuidadosa e convincente como Allen reconstrói e desconstrói essas obras para mostrar como, todas as negações em contrário, cada uma delas se baseia, de maneiras não triviais, na afirmação de que a modernidade foi uma era de progresso histórico, desenvolvimento, evolução social ou aprendizagem sociocultural (SHARPE, 2019, p. 190).

A relevância da obra é crescente no mundo acadêmico, de modo que muitos são os debates traçados em simpósios, congressos e nas salas de aula sobre as proposições da autora em seu livro. O presente trabalho exibe um breve escorço acerca da hipótese de Amy Allen, seguido de críticas e questionamentos suscitados pela Professora Claudia Leeb, Professora Associada de Teoria Política da Washington State University, sempre na perspectiva do refinamento argumentativo. 


\section{ESCORÇO DA OBRA ANALISADA}

A primeira parte da obra apresenta conceitos de progresso utilizados pela Teoria Crítica. A primeira geração de teóricos críticos da Escola de Frankfurt, principalmente Walter Benjamin e Theodor Adorno, era reconhecidamente cética quanto ao discurso de progresso. Em sua Nona Tese sobre a Filosofia da História, Benjamin (2007, p. 257-258) retrata o que é chamado de progresso como a "catástrofe continuada, reunindo destroços aos pés do anjo da História". De forma similar, em suas palestras sobre Filosofia da História, Adorno (2006, p. 7) aponta que a catástrofe de Auschwitz "faz com que toda a conversa sobre progresso em direção à liberdade pareça absurda" e faz com que a "mentalidade afirmativa que compartilhe desse entendimento dê a impressão que não consegue encarar o horror face a face, perpetuando-o com isso". Em seu ceticismo quanto ao discurso do progresso, Benjamin e Adorno tiveram o reforço de dois outros pensadores políticos relevantes do século $\mathrm{XX}$, os quais merecem ser chamados "teóricos críticos" no sentido amplo do termo: Hannah Arendt e Michel Foucault. Essas críticas teóricas ao progresso, que tendiam a focar na natureza altamente metafísica da Filosofia da História, que fundamentavam sua argumentação, seguiram a mesma linha da crítica política ao progresso na obra de teóricos pós e decolonialistas, como Frantz Fanon, C. L.R. James, Aime Cesaire, dentre outros, que tornaram evidente o papel altamente ideológico que argumentos como "progresso" e "desenvolvimento" desempenham na justificativa de projetos do Imperialismo e do Colonialismo (ALLEN, 2016, p. 18).

De fato, as diversas vozes que se levantaram para criticar o rumo do progresso no século XX poderiam levar a acreditar que o conceito de progresso já havia sido deixado nas lixeiras empoeiradas da História. E, no entanto, a ideia de progresso está silenciosamente voltando à Teoria Crítica da Escola de Frankfurt. Começando com Jürgen Habermas, teóricos críticos vêm reformulando o conceito de progresso em uma veia mais pós-metafísica, deflacionária, diferenciada e pragmática, no esforço de separá-lo da Filosofia da História tradicional, ao qual estava incorporado anteriormente. Eles também tentaram responder às críticas políticas ao progresso como inerentemente eurocêntrico ou imperialista. Na obra a autora faz um levantamento das principais estratégias que os autores usaram para responder à essa crítica tradicional do progresso e argumenta que elas ainda estão sujeitas a objeções conceituais e políticas. A partir daí, a autora desenha uma alternativa adorniana ou, ainda, 
uma alternativa adorniana-foucaultiana (ALLEN, 2016, p. 18).

Reformulações recentes do conceito de progresso são motivadas, ao menos em parte, pelo pensamento de que a Teoria Crítica depende de forma crucial da noção de progresso. Isto é, não se pode falar em teóricos críticos que não estejam comprometidos, em maior ou menor medida, com alguma noção de progresso.

Portanto, antes da autora retomar as reformulações recentes do conceito de progresso na Teoria Crítica, ela esboça as razões gerais que foram apresentadas para embasar essa posição, dizendo um pouco mais o que "progresso" significa nesse contexto.

Primeiro, o que se pretende dizer com "progresso"? Pode-se falar de progresso em relação a muitos objetivos e parâmetros diferentes. Dada qualquer meta ou objetivo que se possa ter, é possível imaginar quando estamos mais perto ou mais longe de realizá-lo. Nesse sentido, posso falar em "fazer progressos" ao treinar para uma maratona ou terminar o manuscrito de um livro, e tudo o que se precisa para que essas afirmações façam sentido é clareza quanto aos parâmetros utilizados para medir o progresso ou o regresso. O discurso tradicional de progresso histórico, como surgido na tradição iluminista europeia, tendia a reivindicar algo muito mais amplo sobre avanço geral da humanidade de uma condição bárbara e primitiva para um estado mais desenvolvido, avançado, civilizado e iluminado. Como lembra Reinhart Koselleck, o termo "progresso", como utilizado por Kant, "simples e habilmente trouxe toda a complexidade do progresso científico, tecnológico e industrial, bem como aquele envolvendo a moralidade social e mesmo a totalidade da história, a um conceito comum" (ALLEN, 2016, p. 20).

Essas noções tradicionais de progresso dependem de uma ideia metafísica da totalidade da História e, ao menos, da proposição de um ponto de vista em que essa totalidade possa ser compreendida. Reformulações mais recentes da noção de progresso na Teoria Crítica contemporânea da Escola de Frankfurt são muito menos ambiciosas, metafisicamente falando, e muito mais diferenciadas. Embora alguns defensores da noção de progresso ainda queiram defender a ideia de que existe progresso demonstrável, não apenas em domínios científicos, como também em campos morais e políticos - a exemplo de Habermas -, eles enxergam isso como um fenômeno desagregado.

Então não há sentido para pensar que o progresso técnico-científico leva, necessariamente, a progresso moral-político, ou vice-versa. Muito menos que qualquer um deles leva à felicidade. E mesmo no campo político-moral, progresso econômico pode não vir 
acompanhado de progresso moral, político, cultural e assim por diante. Em todos os domínios o "progresso" é entendido em sua forma pós-metafísica, como uma conquista histórica eventual, resultado da agência humana e, por isso, sujeito a retrocessos e regressões.

Duas formas distintas de argumento têm sido oferecidas para sustentar que a Teoria Crítica precisa de uma ideia de progresso para ser genuinamente crítica. O primeiro argumento sustenta que precisamos da ideia de progresso em relação a um objetivo como forma de dar algo para lutar por, politicamente falando. Ou seja, como forma de tornar nossa política genuinamente progressista. O progresso entendido dessa forma está ligado à famosa terceira pergunta de Kant: “o que me é permitido esperar?”. Para que uma teoria seja crítica, defende o argumento, ela precisa estar conectada à esperança de uma sociedade significativamente melhor, mais justa ou, ao menos, menos opressora. Essa esperança serve para guiar o esforço político, e para que sejam válidas como esperanças genuínas, elas precisam estar fundadas na crença, na possibilidade de progresso. Poderíamos encarar esse posicionamento como um argumento transcendental. Quando um teórico é crítico em relação a algo existente no mundo político ou social, ele precisa, necessariamente, pressupor um ideal à luz do qual faz sua crítica. E ele, o teórico, precisa estar comprometido com essa proposta, de que alcançar esse ideal constituiria progresso de ordem moral, política ou mesmo normativa. Nesse contexto, defende a autora, uma diferenciação entre moral, político ou normativo não faz diferença (ALLEN, 2016, p. 24).

O segundo motivo apresentado para que a Teoria Crítica esteja ligada a uma ideia de progresso envolve um argumento transcendental distinto, mas relacionado. É um argumento encontrado na obra de Axel Honneth, principalmente no seu ensaio "The irreducibility of progress" e no livro "Pathologies of Reason". A ideia aqui é que, na medida em que teóricos críticos louvam ou valorizam certos eventos políticos, como a Revolução Francesa, eles necessariamente veem esses acontecimentos como algo superior ao que veio antes. Ao fazer isso, eles se comprometem com a conclusão de que ao menos algumas características do seu mundo social e político são resultado de um processo progressivo de aprendizado histórico ou anterior (ALLEN, 2016, p. 66).

Esses dois argumentos - um mais orientado para o futuro sobre o progresso ser necessário para tornar a política progressista, o outro que contempla mais o passado, sobre como nós nos situamos no processo de aprendizado histórico para fazer julgamentos críticos -, costumam estar intimamente interligados na Teoria Crítica contemporânea da Escola de 
Frankfurt. A autora ressalta que existem duas concepções distintas de progresso implícitas nesses argumentos. A primeira concepção é voltada para o futuro, onde o progresso é um imperativo político-moral, uma meta normativa que estamos nos esforçando para alcançar. Uma meta que pode ser apreendida sob a ideia da sociedade "boa" ou "mais justa" ou "menos injusta”. A outra concepção foca no passado. Por essa perspectiva, o progresso é o julgamento do processo de desenvolvimento que culminou em nós. Um julgamento que considera nossa concepção de razão, nossas instituições político-morais, nossas práticas sociais, nossa forma de vida e assim por diante, como o resultado de um processo de desenvolvimento sociocultural ou de aprendizado histórico. A autora chama a concepção voltada para o futuro de "progresso como imperativo", e a focada no passado de "progresso como fato". Essas duas concepções estão intimamente ligadas a um conceito de normatividade, e a possibilidade de padrões e princípios que permitam julgamentos normativos trans históricos. Nesse sentido, elas necessariamente convergem. Ambos os argumentos do porquê a Teoria Crítica precisa de uma concepção de progresso também trazem a possibilidade de um tipo específico de progresso, qual seja, político-moral ou normativo, em contraposição à ideia de progresso técnico- científico, ou uma ideia mais geral de como aumentar a felicidade, ou algo nesse sentido. Então é nisso que a autora foca: na possibilidade de algo como progresso normativo e como esse conceito pode ser enunciado.

Nos trabalhos mais recentes da Teoria Crítica, no que a autora chama de progresso com foco no passado, que encara o progresso como um fato, há um esforço não reconhecido, ou não suficientemente valorizado, de fundamentar a normatividade da Teoria Crítica e, com isso, justificar a noção de progresso como um imperativo.

Esse entrelaçamento entre os dois ideais de progresso é resultado mais ou menos direto da combinação de dois comprometimentos. Primeiro, o comprometimento com a ideia de que a perspectiva normativa da Teoria Crítica precisa ser respaldada intrinsicamente no mundo social existente. Segundo, o desejo de evitar o mal do fundacionalismo, de um lado, e do relativismo, do outro. Esses dois comprometimentos estão, de fato, em tensão, já que a tentativa de fundamentar a perspectiva normativa da Teoria Crítica no mundo social existente inevitavelmente levanta preocupações quanto ao convencionalismo e distorções ideológicas. Como saber se os princípios normativos encontrados no mundo social existente são bons ou merecedores do nosso apoio? Talvez eles estejam ideologicamente distorcidos ou reflitam simplesmente como as coisas acontecem por aqui e, portanto, não alcancem um caráter 
genuinamente crítico. Então a estratégia neo-hegeliana, em linhas gerais, baseada na normatividade enraizada, favorecida por Habermas e Honneth, para a autora, é uma tentativa de solucionar essa tensão. A ideia básica é que os princípios normativos que encontramos no nosso mundo social como herdeiros do projeto iluminista europeu ou o legado da Modernidade europeia - que têm um conceito determinado de autonomia racional, no caso de Habermas, ou liberdade social, no caso de Honneth -, são, eles mesmos, justificados, ao menos em parte, à medida que eles podem ser entendidos como resultado de um processo de evolução social progressiva ou de aprendizado sociocultural ou histórico. Portanto, essa concepção de progresso normativo, segundo a autora, permite que a Teria Crítica compreenda os padrões normativos que existem no mundo social não apenas como contingentes ou arbitrários, mas, sim, como justificados à medida que eles resultam de um processo de desenvolvimento histórico ou de aprendizado.

Mas se a fundamentação dos teóricos críticos no mundo social repousa, em última instância, num argumento sobre evolução social ou processos de aprendizado sociocultural, isso significa que os padrões normativos que permitem que a perspectiva de uma sociedade boa ou mais justa, no caso de Habermas, algo como o princípio do discurso ou, no caso de Honneth, a ideia de liberdade social ou reconhecimento, eles próprios são justificados, ao menos em parte, desde que produtos de um processo de desenvolvimento sociocultural ou aprendizado. Em outras palavras, as duas concepções de progresso que a autora tentou diferenciar estão relacionadas: aquele progresso como um imperativo político-moral é, para Habermas e Honneth, fundado na orientação normativa básica que é posta em xeque com a concepção de progresso como um fato histórico. Em outras palavras, a perspectiva normativa que serve para orientar a concepção voltada para o futuro de progresso na Teoria Crítica contemporânea é justificada pela posição focada no passado sobre como nasce a iluminação europeia moderna, vocabulário moral de ideais políticos que são o resultado de um processo de aprendizado e, por isso, nenhum deles é fruto de uma simples convenção ou fundado em uma concepção apriorística transcendental de pura razão prática. Essa orientação normativa nos fornece uma concepção da sociedade "boa" ou "mais justa" que configura a base para nossas aspirações político-morais. Isso sugere que, ao menos em relação a como a ideia de progresso tem sido usada na obra de Habermas e Honneth, essas duas concepções de progresso, a voltada para o futuro, como um imperativo, e a focada no passado, como um fato, um aprendizado histórico, não podem ser facilmente separadas. Em outras palavras, não é 
possível para essa corrente da Teoria Crítica segurar-se ao seu entendimento de progresso como imperativo político-moral sem manter intacta ou defender a noção de progresso como fato, desde que a normatividade da Teoria Crítica seja assegurada por meio da história de evolução sociocultural ou aprendizado histórico. Então a Teoria Crítica contemporânea concebida por Habermas e Honneth só pode ser resolvida do seu comprometimento com o progresso se também se propuser a repensar seu entendimento de normatividade, e é a isso que a autora se dedica no desfecho da sua obra (ALLEN, 2016, p. 70).

Mas, primeiro, por que pensar que uma solução dessas é necessária? O que, afinal, é problemático na ideia de progresso como fato e no papel que essa ideia está desempenhando na justificativa da função da Teoria Crítica? Dois tipos de objeção são particularmente salientes aqui: a primeira, conceitual, e a segunda, político. A questão conceitual volta-se para o seguinte tipo de pergunta: quais bases utilizamos para decidir o que conta como progresso nas análises da História? O julgamento sobre progresso normativo como uma afirmação de aprendizado histórico ou desenvolvimento não presume um conhecimento sobre o que representa o "ponto final" ou a meta desse desenvolvimento histórico? Nesse ponto, os julgamentos sobre progresso normativo não acabam pressupondo um padrão normativo independente, não-histórico, transcendente a contextos sob risco de cair no convencionalismo que tentam tão avidamente evitar? A preocupação aqui é que, sem um padrão independente, julgamentos sobre progresso normativo tornar-se-iam, como Charles Larmore aponta, “irremediavelmente paroquiais", nada além de "um instrumento de auto-felicitação". Então a ideia básica aqui é que é difícil ver como uma história sobre progresso normativo ligado à ideia de evolução histórica ou sociocultural ou aprendizado seria possível sem um ponto de vista independente ou transcendente a contextos, um ponto de vista extra-histórico, o que tanto Habermas quanto Honneth refutam. Mas, por outro lado, se não levarmos esse padrão em consideração o argumento sobre aprendizado histórico e progresso torna-se invariavelmente circular. Isso significa que estaríamos nos felicitando por ter alcançado certos princípios que, por sua vez, podem servir de padrão para julgamentos de progresso normativo ou político-moral (ALLEN, 2016, p. 28).

A autora passa então a objeção política, que diz respeito à interrelação entre a ideia de progresso como fato, a concepção focada no passado, e os legados do racismo, colonialismo e imperialismo e as suas formas contemporâneas, o neo-colonialismo e o neoimperialismo. Aqui, a autora reforça que o problema não é o conceito de progresso histórico 
em si, mas a própria história do progresso que Habermas e Honneth querem contar. Porque essa é uma história sobre iluminismo europeu e a Modernidade europeia como sendo eles mesmos resultado de um processo progressivo de aprendizado histórico. Não é apenas uma afirmação sobre haver progresso de um ponto a outro da história, é uma história que, no modo de entender da autora, procura justificar o ponto de vista que surge na Modernidade e no Iluminismo europeus. É essa história particular que parece sujeita a essa objeção política. A ideia de que os ideais normativos do Iluminismo europeu são resultado progressivo de um processo de aprendizado por meio do qual a Modernidade emergiu a partir de formas de vida tradicionais, é desconfortavelmente próxima da lógica eurocêntrica que serviu para justificar o colonialismo e a assim chamada "missão civilizadora". Isso não é original da autora e já foi postulado de diversas teorias pós-colonialistas e decolonialistas. Não é um argumento original, mas a autora entendeu importante retomar como a objeção política pode ser identificada repetidas vezes nesse corpo da literatura. Obras que identificam esse eurocentrismo são, por exemplo, as de Edward Said, vindo de uma perspectiva do sudeste asiático, e de Enrique Dussel, da perspectiva latino-americana.

Nas palavras de James Tully, "a língua do progresso e do desenvolvimento é a língua da opressão para dois terços da população mundial". Em outras palavras, a noção do progresso histórico como fato está ligada a questões complexas como dominação, exclusão e silenciamento de sujeitos colonizados e subalterno. Essas duas formas de objeção, a conceitual e a política, podem vir e geralmente vêm juntas, principalmente em críticas póscoloniais do progresso que seguem a linha de Michel Foucault e a ideia da interrelação entre poder e conhecimento. De fato, a segunda objeção, a objeção mais política, poderia ser vista como uma especificação adicional da primeira objeção, ou seja, uma forma particular de autofelicitação, endêmica à concepção europeia de progresso histórico (ALLEN, 2016, p. 19).

À luz dessas objeções, pode-se lançar mão de outra estratégia para entender o relacionamento entre progresso e normatividade. A estratégia construtivista neo-kantiana aprimorada por Rainer Forst retém a ideia do progresso como imperativo, mas sem depender da visão histórica neo-hegeliana focada no passado, do progresso como fato. Em contraposição a isso, Forst articula um padrão político-moral universal que ele denomina "o direito básico à justificação", que se fundamenta não na visão focada no passado sobre progresso histórico, e sim em uma razão prática autônoma. Forst argumenta ainda que o progresso é um conceito normativamente dependente, no sentido de que ele depende de um 
padrão normativo universal, que pode prover um parâmetro claro para afirmações sobre progresso histórico. Portanto, muito embora a estratégia neo-kantiana possa possibilitar afirmações de progresso como fato talvez, em certa medida, ela até necessite delas, no sentido de que uma vez articulado um padrão normativo universal, certos julgamentos sobre progresso e regresso estão abarcados por ele, a estratégia pode possibilitar esse tipo de noção, mas ela não depende da utilização disso para justificar os seus próprios padrões normativos. Eu acredito que essa forma de entender o relacionamento entre normatividade e progresso histórico realmente evita a confusão entre a lógica voltada para o futuro e o foco no passado enfrentada por Habermas e Honneth. Nesse sentido, evita também a objeção conceitual que a autora expôs anteriormente. Mas, ao fazê-lo, abre-se uma brecha para uma versão diferente da objeção política, uma objeção fundamentada na preocupação de que todo e qualquer padrão normativo universal, transcontextual, ou concepções de razão prática são, em última instância, concepções substantivas do "bom" disfarçadas. Portanto, de forma bastante esquemática, para respeitar o tempo, a preocupação é a moralidade kantiana abstrata e a razão prática sejam apenas eurocentrismo disfarçado, parte da tendência ocidental de se considerar "o universal". Aqui a autora está citando a filósofa feminista Linda Alcoff em seu discurso recente como presidente da Associação Filosófica Americana. Uma versão mais sofisticada desse argumento alega que muito trabalho substantivo tem sido feito em virtude da razão prática, e julgamentos acerca de quem é ou não razoável e, portanto, quem é ou não capaz de ser um interlocutor discursivo também contribuiu muito, em termos de função política, em favor dos poderosos. A noção de razão prática, se for para ser densa e substantiva o suficiente para levar a cabo o trabalho normativo que a força exige provavelmente excluirá, nas palavras de Edward Said, "figuras subalternas como mulheres, negros das Antilhas ou outros nativos" que tiveram de fazer muito barulho de forma não- razoável antes de serem admitidos na comunidade como seres que argumentam. Uma segunda objeção, mais metodológica, sustenta que a abordagem da força sacrifica a particularidade da Teoria Crítica enquanto abordagem metodológica. Principalmente ao abdicar do comprometimento teórico crítico em relação à ideia de que princípios normativos devem ser encontrados na realidade social existente. E que, ao adotar uma abordagem mais fundacionalista da normatividade, esquece-se que essa foi justamente a razão pela qual os teóricos críticos voltaram-se para o discurso do progresso como fato em um primeiro momento (ALLEN, 2016, p. 113).

Nesse ponto, a autora apresenta a alternativa adorniana proposta. À luz dessas 
propostas, defende uma forma diferente de solucionar a confusão entre progresso como um imperativo político-moral e o progresso como fato. A autora chama essa estratégia de adorniana não apenas por ser inspirada na ideia de Adorno de que o progresso ocorre apenas onde termina, mas também porque ela parte da sua tentativa de desenvolver uma Filosofia da História que não é nem progressista nem regressista. Na sua tentativa de enraizar esse entendimento da História em uma abordagem anti-fundacionalista, historicamente situada, da normatividade. Este esforço pode ser considerado bastante compatível com os resultados encontrados por Foucault no estudo de História e normatividade, e, nesse sentido, a estratégia da autora também poderia ser chamada adorniana-foucaultiana. O principal avanço conceitual da estratégia é tentar avançar com uma concepção de normatividade muito mais antifundacionalista e contextualizada. Essa concepção, segundo a autora, ainda permite que surjam aspirações de progresso político-moral voltadas para o futuro, mas também entende todas as aspirações ao progresso como extremamente transitórias, fundadas na posição metanormativa contextualista e, como tal, sempre necessitando de problematização genealógica constante. Essa posição conseguiria, assim, concordar com o argumento transcendental de que alguém apenas pode ser contra o progresso ao ser a favor dele - esse é um argumento de Rainer Forst em seu ensaio sobre progresso. Em outras palavras, ele consegue acatar a pretensão de que a crítica pós- colonial de concepção ideológica de progresso como fato está implicitamente comprometida com a pretensão de que seria melhor se nós nos retirássemos dessa concepção e, com isso, é implicitamente comprometida com alguma ideia de progresso. No entanto, a estratégia parte do pressuposto de que qualquer aspiração que possa ser atendida como progresso está constantemente sujeita à problematização (ALLEN, 2016, p. 125).

A autora desenvolve a ideia de progresso voltado para o futuro em relação ao conceito de emancipação, sem utopia, um entendimento negativista acerca da diminuição de relações de dominação, que considera um entendimento mínimo que faz nossas aspirações de progresso menos robustas. Então se aceitarmos a ideia de que a Teoria Crítica é um projeto iminente e reconstrutivo, que retira seu conteúdo normativo de dentro da realidade social, e se rejeitarmos a estratégia neo-hegeliana para afirmar uma postura ao mesmo tempo em que evitamos o fundacionalismo, então a autora acredita que isso necessariamente nos move em direção a uma normatividade mais contextualizada, no nível meta-ético ou meta-normativo. Assim, muito do argumento estruturalista da obra é mesmo um processo de eliminação. A 
autora começa com alguns pressupostos metodológicos da Teoria Crítica, além da questão sobre como fundamentar uma concepção de normatividade, analisando a estratégia neohegeliana, verificando os problemas que aparecem.

É claro que muito mais poderia e deveria ser dito sobre, "se" e "como" essa concepção de normatividade consegue evitar descambar em relativismos ou outros "ismos". A autora defende que isso tem que ficar claro para evitar a confluência com a teoria normativa de primeira ordem e a meta-ética ou história meta-normativa sobre justificação, que é proeminente em grande parte da literatura da Teoria Crítica.

Um dos argumentos centrais do livro é que princípios normativos universalistas de primeira ordem podem ser fundamentos em uma gama de posições meta-éticas, incluindo posições contextualizadas e coerentistas. Ainda, trabalhando em outra direção, pode-se argumentar que o fato de o comprometimento normativo de primeira ordem da Teoria Crítica equivaler a respeito moral mútuo, inclusão, e assim por diante, acaba por empurrá-la em direção a uma meta-ética mais modesta e apagada, se comparada tanto à estratégia neohegeliana quanto à neo-kantiana que a autora discutiu anteriormente. A sugestão aqui é que se tomarmos como ponto de partida o comprometimento transitório de normatividade, de respeito moral mútuo, inclusão e abertura ao próximo e, a partir daí, afastarmo-nos da posição normativa que é mais compatível com esses comprometimentos, como a da nossa concepção de que eles são transitórios, então terminaremos com uma posição contextualizada metanormativa e epistemologicamente humilde. Essa posição reconheceria, como coloca Judith Butler, que "se o ser humano é alguma coisa, ele parece ser um movimento duplo, em que assentimos com certas normas morais, ao mesmo tempo em que questionamos a autoridade com a qual fazemos o assentimento". Portanto, essa posição meta-normativa requer uma humildade epistemológica - essa humildade epistemológica vem no sentido meta-normativo, ou seja, quando falamos de princípios de primeira ordem. Ela vai além do falibilismo, e por falibilismo entende a autora a consciência de que nós podemos errar. Isso é mais forte que o falibilismo, porque engloba uma problematização constante, ativa e crítica do nosso próprio ponto de vista, tendo por objetivo alcançar mais plenamente os ideais de liberdade, respeito mútuo, abertura, inclusão e assim por diante - em ralação ao nosso próprio ponto de vista (ALLEN, 2016, p. 140).

No tocante a ideia de progresso como fato, muito embora uma concepção contextualista e anti-fundacionalista pudesse, ao analisar o passado, considerar o progresso 
um fato, essas seriam considerações modestas sobre o nosso progresso ou "para nós", ou seja, em relação a certos parâmetros normativos aos quais estamos sujeitos, embora essas considerações possam ser conceitualmente coerentes, elas ainda estão sujeitas a algumas das objeções acerca da tendência à auto-felicitação, viés do status quo e outras objeções discutidas anteriormente. Para a autora o "antídoto" adequado a essa tendência à auto-felicitação é um entendimento diferente do papel da genealogia dentro da Teoria Crítica. Nessa concepção, a genealogia não tem por objetivo nem a subversão direta nem a denúncia de nossos conceitos e princípios normativos, tampouco uma reivindicação. Ao invés disso, a genealogia teria por objetivo o que a autora chama de "a problematização de um ponto de vista normativo", onde essa problematização requer uma combinação de reivindicação, subversão, ou leituras progressistas e regressistas da História.

Então, a partir das obras de Foucault e Adorno, no final do livro, a autora argumenta que o verdadeiro objetivo ao problematizar a genealogia inclui não apenas as instâncias empíricas de nossos ideais normativos e concepções de razão, mas também os tipos de violência epistêmica contida nos próprios ideais e concepções de razão. Então aqui a autora está tentando delimitar seu entendimento de genealogia, tanto em relação a como Habermas usou o termo - que, na leitura da autora, é bem mais direto e reivindicatório -, em que a genealogia serve para defender e reivindicar nossos princípios normativos, como também a autora tenta diferenciar seu entendimento do de Honneth, que fez uso da genealogia no seu ensaio "Reconstructive Social Critique with a Genealogical Reservation: on the idea of Critique in the Frankfurt School", porque ele também aponta a importância da genealogia, mas em um papel mais limitado, porque a genealogia pode nos dizer onde nossos ideais normativos deram errado na prática. A autora defende que a genealogia é necessária para desempenhar um papel mais relevante na discussão de quais princípios podem estar entranhados com relações de poder e violência.

No entanto, em uma virada reflexiva posterior, a autora alega que o papel problematizador da genealogia é especialmente importante na compreensão de qual tipo de respeito e abertura para o próximo, que parecem ser centrais à herança normativa do iluminismo, merecem atenção. De forma paradoxal, a autora argumenta que problematizar toda e qualquer afirmação de progresso como fato é, na verdade, a melhor forma de fazer jus ao legado da Modernidade, principalmente em relação às noções de liberdade, inclusão e respeito moral mútuo. A autora assume que a objeção política ao discurso do progresso como 
fato discutido anteriormente é persuasiva, exceto no tocante à noção progressista desenvolvimentista em que progresso como fato é, a seu ver, inconsistente com a incorporação do valor "respeito moral mútuo", porque ela nos força a encarar outros humanos como imaturos, não desenvolvidos e, como consequência disso, incapazes de governar-se a si próprios de forma autônoma. Respeito genuíno pelo outro e abertura ao outro exige, portanto, a problematização genealógica constante do nosso entendimento de nós mesmos enquanto herdeiros do projeto normativo do Iluminismo. Ele requer o que Gayatri Spivak chamou de constante, persistente, vigilante "crítica do que nós não podemos não querer" (ALLEN, 2016, p. 109).

\section{CONTRIBUIÇÕES, ANÁliSES E CRÍTICAS DE CLAUDIA LEEB À OBRA DE AMY ALLEN}

Comentado o capítulo cinco do livro - quando Amy Allen traz um teórico crítico da Escola de Frankfurt, Theodor W. Adorno, em conversa com o pensador francês Michael Foucault para construir seu próprio quadro teórico que nos permite fundamentar a teoria crítica em uma ideia de normatividade que escapa à acusação de eurocentrismo - a professora Claudia Leeb apresenta algumas questões relevantes.

O primeiro possível problema observado é que as suposições "sobre os outros culturais", especialmente sobre os "outros raciais" são feitas no nível inconsciente ou préconsciente e não tanto no nível discursivo nas interações diárias. A professora pergunta se o modelo de Allen de fundamentar a normatividade na ideia de humildade se beneficiaria de uma explicação psicanalítica do inconsciente, que nos mostra que mesmo quando tentamos refletir conscientemente sobre nossos compromissos normativos e ser humildes sobre eles, ainda podemos nutrir a convicção inconsciente de que somos moral e politicamente superiores aos "outros raciais", o que se desenrola no diálogo de outras maneiras, como reações físicas aversivas em relação a esses (LEEB et al. 2016, p. 05).

Uma segunda questão é que Allen não se compromete ou busca uma leitura textual atenta dos textos de Marx. Seu envolvimento com Marx ocorre principalmente por meio da leitura unilateral feita por Habermas sobre Marx, em seus primeiros trabalhos. No entanto, já em A Ruthless Critique of Everything Existing, Marx atacou qualquer prefiguração dogmática do futuro e qualquer noção de uma utopia comunista. Além disso, no Manifesto do Partido 
Comunista, Marx deixa claro que qualquer ideia de progresso nas sociedades capitalistas está ligada à violência da empresa colonial que explora novos mercados e ao projeto liberal burguês que reduz o resto do mundo a uma imagem de si mesma por meio de sua "missão civilizadora". Além disso, para Marx, o desenvolvimento das forças de produção não implica uma noção incontestável de progresso. Em vez disso, ele ataca esse desenvolvimento em todas as suas obras, uma vez que serve apenas aos capitalistas, porque lhes permite sugar totalmente os poderes físicos e mentais dos trabalhadores como um meio de aumentar seu próprio poder, riqueza e status na sociedade capitalista (LEEB et al. 2016, p. 06).

Além disso, Marx não sugeriu que o desenvolvimento histórico das forças produtivas estimulado pelo conhecimento técnico-científico seja o motor do "progresso histórico", como sugere Allen via Habermas (ALLEN, 2016, p. 45). Em vez disso, permite que a classe capitalista explore o proletariado de maneiras cada vez mais insidiosas, com formas cada vez mais sofisticadas de racionalização tecnológica. Marx não propôs um progresso fácil do capitalismo ao comunismo por meio da agência revolucionária do proletariado que não permite qualquer contingência. Em vez disso, Marx no Manifesto do Partido Comunista deixou claro que a luta revolucionária do proletariado tem muitos reveses (LEEB et al. 2016, p. 06).

A preocupação central de Leeb (2016, p. 06) com a sugestão de Allen de que devemos nos afastar de Marx é que ela se encontra aberta à crítica de que ela própria abandona uma crítica rigorosa do capitalismo. Aqui, Allen, em vez de corrigir a tendência problemática da escola contemporânea de Frankfurt de abandonar uma crítica rigorosa do capitalismo, que ela mesma observa como um problema (ALLEN, 2016, p. 40), parece reforçar essa tendência. Além disso, aborda as maneiras pelas quais os próprios impulsos radicais de Adorno, que são principalmente perdidos na teoria crítica contemporânea da Escola de Frankfurt com sua evasão do pensamento marxista (bem como do pensamento psicanalítico), são devedores de seu envolvimento com Marx. Além disso, um afastamento de Marx pode não servir à abertura da teoria crítica para a teoria pós-colonial, na medida em que a própria teoria pós e decolonial encontrou recursos centrais em Marx para teorizar a dominação colonial e a possibilidade de conter tal dominação. Sugiro que o próprio relato de Allen de fundamentar a teoria crítica em uma noção mais ambivalente de progresso poderia ganhar voltando-se para Marx em vez de se afastar dele.

Em outra indagação, Leeb (2016, p. 07) questiona à busca de Allen por uma crítica 
imanente em seu livro, o que implica que sua abordagem da teoria crítica está situada na tradição intelectual da Escola de Frankfurt, e que ela pretende recorrer aos recursos da Escola de Frankfurt (principalmente Adorno) para decolonizar a teoria crítica contemporânea da Escola de Frankfurt. Embora eu simpatize com seu projeto de trazer Foucault para uma conversa com Adorno para desenvolver sua estrutura alternativa de normatividade fundamental, estou me perguntando se isso equivaleria a uma transformação mais radical da teoria crítica da Escola de Frankfurt recorrer à própria teoria pós-colonial para construir sua alternativa quadro teórico no capítulo cinco.

Em outras palavras, em vez de recorrer a dois pensadores europeus do sexo masculino, brancos, que têm seus próprios problemas com o eurocentrismo, que Allen também observa, e se ela tivesse escolhido uma ou talvez duas teóricas feministas pós ou decoloniais para construir um quadro teórico alternativo? Basear-se na teoria feminista pós e decolonial para fornecer sua própria explicação de fundamentar a teoria crítica em uma ideia de normatividade teria permitido a Allen incluir "Outros raciais" no "espaço da razão", o que, como ela descreve na conclusão, é central para combater o eurocentrismo (LEEB et al. 2016, p. 07).

Além disso, talvez seja um problema sustentar o conceito de "liberdade" como o conceito central para a teoria crítica, na medida em que este conceito, como ela própria expõe, está vinculado ao projeto colonial europeu, que surgiu como um ideal alardeado pelos pensadores iluministas da época em que a Europa iniciou seu projeto capitalista de escravizar os não europeus em suas colônias (ALLEN, 2016, p. 18). Além disso, Marcuse (2002) nos mostra que as elites capitalistas, neoliberais, continuam a martelar essa frase nas mentes daqueles que exploram para encobrir sua falta de liberdade na exploração capitalista. Poderia a teoria feminista pós e decolonial oferecer alternativas e conceitos mais promissores e menos vinculados ao projeto capitalista colonial?

Por derradeiro, o último questionamento de Leeb diz respeito à promessa de Allen, no primeiro capítulo de seu livro, sobre decolonizar a teoria crítica contemporânea da Escola de Frankfurt, mas também sobre mostrar como a teoria pós e decolonial pode ser criticada, o que permitiria a utilização de tal teoria para responder efetivamente à acusação de longa data do relativismo (ALLEN, 2016, p. 06). Allen certamente faz um excelente trabalho com a decolonização da teoria crítica. No entanto, sua tentativa de criticar a teoria pós e decolonial aparece apenas na conclusão, na última página do livro (LEEB et al. 2016, p. 08). 


\section{CONCLUSÃO}

Como visto, The End of Progress toma como ponto de partida a crítica do eurocentrismo formulada pela teoria pós-colonial. Allen observa o paradoxo de que os teóricos críticos na tradição da Escola de Frankfurt perseguem tópicos como justiça global e direitos humanos sem refletir sobre os fundamentos coloniais dos conceitos de progresso e desenvolvimento histórico.

Como os teóricos pós-coloniais têm mostrado repetidamente, os esquemas civilizacionais que tratam o espaço euro-atlântico como mais desenvolvido do que o resto do mundo estão enredados na lógica colonial e racista. É relevante a rejeição de Allen quando à teleologia do progresso e sua crítica ao conceito do Iluminismo como resultado do aprendizado moral.

As contribuições trazidas por Claudia Leeb à obra de Amy Allen são ricas e refletem o amplo conhecimento da professora quanto aos alicerces da Escola de Frankfurt e o seu trabalho na teoria política feminista e na teoria psicanalítica para abordar questões de poder e mudança sociopolítica nas sociedades contemporâneas.

A ideia de que o modelo de Allen se beneficiaria de uma explicação psicanalítica do inconsciente; os questionamentos quanto à tentativa de Allen de que devemos nos afastar de Marx para trabalhar sua tese; a necessidade de subsidiar sua pesquisa nas bases da própria Escola Frankfurt; e possibilidade de aprofundamento da sua pesquisa com a crítica das teorias pós e decolonial, são todas indagações qualificadas que podem enriquecer a obra em uma possível extensão da pesquisa.

Sua leitura é generosa no sentido de que aprecia o que o livro busca realizar, o que não a impede de fazer críticas incisivas. Isso por si só já contribui na abertura de um tipo diferente de conversa entre a Teoria Crítica da Escola de Frankfurt contemporânea e teorias críticas (incluindo teorias anticoloniais) no sentido mais amplo desse termo. O fato de o livro estar sendo levado de várias direções diferentes indica que ele teve sucesso nessa empreitada.

\section{REFERÊNCIAS}

ADORNO, Theodor. History and Freedom: Lectures, 1964-1965. Edited by Rolf Tiedemann. Translated by Rodney Livingstone. Cambridge: Polity, 2006. 
ALLEN, Amy. The End of Progress: Decolonising the Normative Foundations of Critical Theory. New York: Columbia UP, 2016.

BENJAMIN, Walter. Illuminations: Essays and Reflections. Translated by Harry Zohn. New York: Schocken, 2007.

LEEB, Claudia; NICHOLS, Robert; WINTER, Yves; ALLEN, Amy. Liberating Critical Theory: Eurocentrism, Normativity, and Capitalism. Symposium on Amy Allen's The End of Progress: Decolonizing the Normative Foundations of Critical Theory, Columbia University Press, v. 46, issue 5, page(s): 772-800, 2016.

MARCUSE, Herbert. One-Dimensional Man: Studies in the Ideology of Advanced Industrial Society, 2nd ed. New York: Routledge, [1964] 2002.

SHARPE, Matthew. From Amy Allen to Abbé Raynal: Critical Theory, the Enlightenment and Colonialism, Critical Horizons, 20:2, 178-199, 2019.

AZMANOVA, A.; SAAR, M.; TREIBER, G. et al. Emancipation, Progress, Critique: Debating Amy Allen's The End of Progress. Contemp Polit Theory 17, 511-541, 2018. 